\title{
X-Ray Imaging of SAPO-34 Molecular Sieves at the Nanoscale: Influence of Steaming on the Methanol-to- Hydrocarbons Reaction
}

\author{
Luis R. Aramburo, ${ }^{[a]}$ Javier Ruiz-Martínez, ${ }^{[a]}$ Linn Sommer, ${ }^{[b]}$ Bjørnar Arstad, ${ }^{[c]}$ \\ Robison Buitrago-Sierra, ${ }^{[\mathrm{d}]}$ Antonio Sepúlveda-Escribano, ${ }^{[\mathrm{d}]}$ Henny W. Zandbergen, ${ }^{[\mathrm{e}]}$ \\ Unni Olsbye, ${ }^{[b]}$ Frank M. F. de Groot, ${ }^{[a]}$ and Bert M. Weckhuysen*[a]
}

The effect of a severe steaming treatment on the physico-
chemical properties and catalytic performance of H-SAPO-34
molecular sieves during the methanol-to-hydrocarbons (MTH)
reaction has been investigated with a combination of scanning
transmission X-ray microscopy (STXM), catalytic testing, and
bulk characterization techniques, including ammonia tempera-
ture programmed desorption and ${ }^{27} \mathrm{Al}$ and ${ }^{29} \mathrm{Si}$ magic angle
spinning nuclear magnetic resonance. For this purpose, two
samples, namely a calcined and a steamed H-SAPO-34 catalyst
powder, have been compared. It has been found that calcined
$\mathrm{H}$-SAPO-34 displays a high selectivity towards light olefins, yet
shows a poor stability as compared to a zeolite H-ZSM-5 cata-
lyst. Moreover, in situ STXM at the carbon K-edge during the
MTH reaction allows construction of nanoscale chemical maps
of the hydrocarbon species formed within the H-SAPO-34 ag- gregates as a function of reaction time and steam post-treatment. It was found that there is an initial preferential formation of coke precursor species within the core of the H-SAPO-34 aggregates. For longer times on stream the formation of the coke precursor species is extended to the outer regions, progressively filling the entire H-SAPO-34 catalyst particle. In contrast, the hydrothermally treated H-SAPO-34 showed similar reaction selectivity, but decreased activity and catalyst stability with respect to its calcined counterpart. These variations in MTH performance are related to a faster and more homogeneous formation of coke precursor species filling up the entire steamed H-SAPO-34 catalyst particle. Finally, the chemical imaging capabilities of the STXM method at the Al and Si Kedge are illustrated by visualizing the silicon islands at the nanoscale before and after steaming H-SAPO-34.

\section{Introduction}

The methanol-to-hydrocarbons (MTH) process has increasingly attracted both academic and industrial interest as it represents

[a] Dr. L. R. Aramburo, Dr. J. Ruiz-Martínez, Prof. Dr. F. M. F. de Groot,

Prof. Dr. B. M. Weckhuysen

Inorganic Chemistry and Catalysis Group

Debye Institute for Nanomaterials Science, Utrecht University

Universiteitsweg 99, 3584 CG Utrecht (The Netherlands)

Fax: $(+31)$ 030-251-1027

E-mail:b.m.weckhuysen@uu.nl

[b] Dr. L. Sommer, Prof. Dr. U. Olsbye

Centre for Materials Science and Nanotechnology

Department of Chemistry, University of Oslo

N-0315 Oslo (Norway)

[c] Dr. B. Arstad

Department of Process Chemistry

SINTEF Materials \& Chemistry, 0314 Oslo (Norway)

[d] R. Buitrago-Sierra, Prof. Dr. A. Sepúlveda-Escribano

Laboratorio de Materiales Avanzados

Departamento de Química Inorgánica, Universidad de Alicante Apartado 99, E-03080 Alicante (Spain)

[e] Prof. Dr. H. W. Zandbergen

Kavli Institute of NanoScience

National Centre for High Resolution Electron Microscopy

Delft University of Technology

P.O. Box 5046, 2600 GA Delft (The Netherlands)

Supporting information for this article is available on the WWW under http://dx.doi.org/10.1002/cctc.201200670. a promising route to valuable hydrocarbons from methanol. ${ }^{[1-8]}$ Microporous silicoaluminophosphates and aluminosilicates, such as H-SAPO-34 and H-ZSM-5, are archetypal materials for this catalytic process. Nonetheless, the reactivities of these acidic molecular sieves differ considerably and as a consequence they are often used for different purposes. Specifically, H-ZSM-5 catalysts can be used to obtain different sorts of added value chemicals by varying the MTH process conditions, whereas the use of H-SAPO-34 is mainly focused on production of light olefins. ${ }^{[9]}$ Despite the high activity and selectivity of both catalyst materials, an important limitation for their application arises from their susceptibility to deactivation through rapid formation of coke deposits. ${ }^{[10,11]}$ As a result, frequent oxidative treatments are needed to regenerate the catalyst material, limiting the profitability of the MTH process. Additionally, during these treatments important modifications can take place in the physicochemical properties of molecular sieves, which result in substantial variations in their catalytic performance during $\mathrm{MTH}$.

In a recent publication, ${ }^{[12]}$ we used in situ scanning transmission $x$-ray microscopy (STXM) as a novel chemical imaging tool to investigate zeolite $\mathrm{H}-\mathrm{ZSM}-5$ catalyst powders during the MTH reaction before and after applying a severe hydrothermal treatment. With this approach it was possible to establish a re- 
lationship between the bulk catalytic performances and the nanoscopic phenomena taking place in the catalyst particles during MTH reaction. More specifically, it was found that the superior MTH stability of steamed H-ZSM- 5 could be explained by the presence of similar hydrocarbon species homogeneously distributed throughout the catalyst particle. In contrast, calcined H-ZSM-5, displaying a higher MTH activity, but lower stability, possessed a heterogeneous distribution of two hydrocarbon species. Comparison with hydrocarbon reference compounds revealed that the external regions of the calcined $\mathrm{H}$ ZSM-5 aggregate contained more bulky hydrocarbons relative to the inner catalyst aggregate regions. Accordingly, the sudden activity decrease could be explained by the preferential formation of coke precursor species at the external regions of the zeolite aggregate.

In the present study, a similar experimental approach has been used to characterize the physicochemical properties of H-SAPO-34 molecular sieves during MTH reaction. Two samples, namely a calcined H-SAPO-34, further denoted as SAPO34-C, and a steamed H-SAPO-34 with sample name SAPO-34-S, have been investigated with in situ STXM. In this way, the changes in catalytic activity, selectivity, and stability, as observed in both H-SAPO-34 catalyst powders, have been correlated to structural, compositional, and acidic modifications, as measured with STXM, temperature programmed desorption (TPD) with ammonia as a probe molecule, ${ }^{27} \mathrm{Al}$ and ${ }^{29} \mathrm{Si}$ magic angle spinning nuclear magnetic resonance (MAS NMR), nitrogen and carbon dioxide sorption, as well as X-ray Diffraction (XRD). The obtained results will be compared with those for the calcined and steamed H-ZSM-5 catalyst powders. ${ }^{[12]}$

\section{Results and Discussion}

\section{Performance changes by applying a severe hydrothermal treatment}

In a first set of experiments, the catalytic performance of SAPO-34-C was tested during MTH reaction at $400^{\circ} \mathrm{C}$. The catalytic conversion and selectivity patterns are summarized in Figure 1. The catalytic tests showed that SAPO-34-C is characterized by an induction period in the early stages of the MTH reaction. ${ }^{[13]}$ Interestingly, after the induction period the catalyst material did not show a full methanol conversion, but rather a conversion close to $80 \%$. The reduced initial catalyst activity is reasonably attributed to the storage and calcination treatment performed after template removal. To corroborate this hypothesis the same catalytic test was performed on a $\mathrm{H}$ SAPO-34 sample that was stored for a period of approximately 3 days after template removal and did not undergo a calcination treatment (sample name: SAPO-34-P). As shown in Figure $1 \mathrm{a}$, this sample presented a better initial catalytic performance than SAPO-34-C. This is in line with literature as it has been reported that the physicochemical properties of H-SAPO34 materials may change after template removal. ${ }^{[14,15]}$ In particular, depending on the storage time and the temperature at which dehydration is performed, the material can undergo irreversible modifications, which lead to a decrease in MTH perfor-
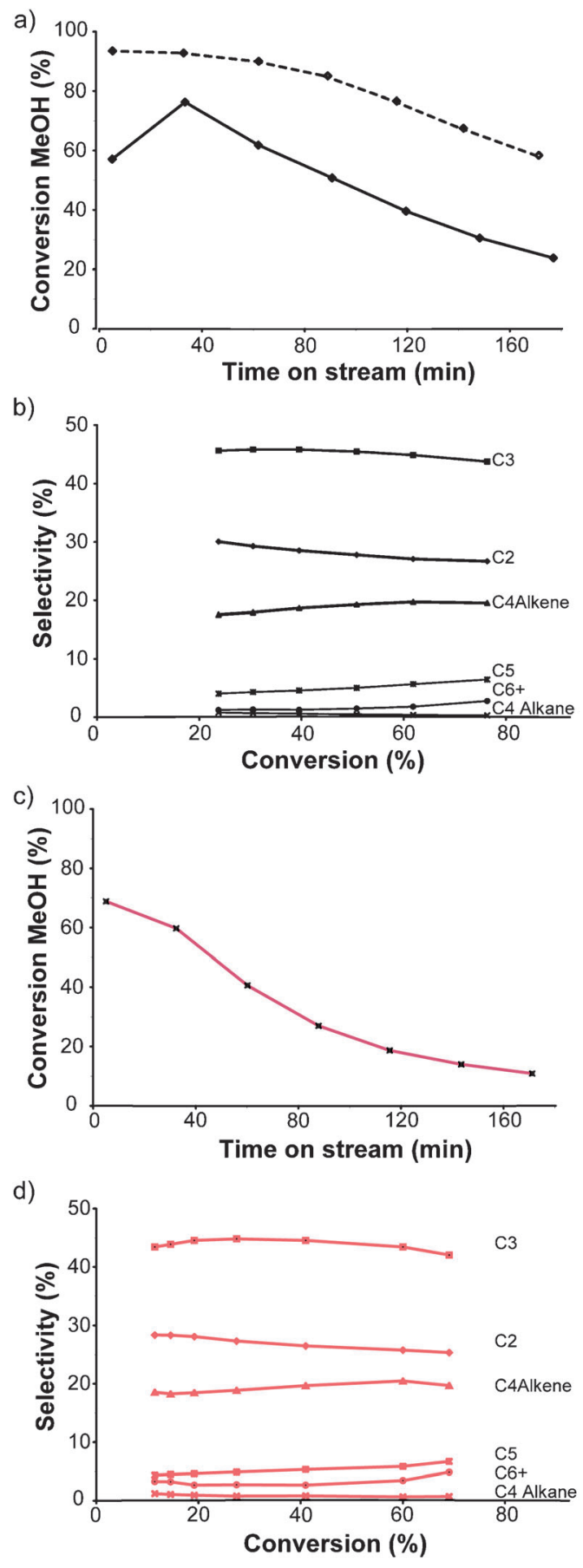

Figure 1. Methanol conversion at $400{ }^{\circ} \mathrm{C}$ over a) SAPO-34-C (solid line) and SAPO-34-P (dash line), and C) SAPO-34-S versus time on stream. Selectivity towards $C_{2}, C_{3}, C_{4}, C_{5}$ and $C_{6}$ versus MTH conversion over b) SAPO-34-C and d) SAPO-34-S at $400^{\circ} \mathrm{C}$.

mance. ${ }^{[16]}$ In agreement with these studies, the conversion of SAPO-34-C rapidly decreased to $30 \%$ after 160 min time on stream. On the other hand, the selectivity pattern of the SAPO34-C sample, shown in Figure $1 \mathrm{~b}$, is typical for H-SAPO-34 materials because of its high selectivity towards light olefins. Furthermore, gas chromatography coupled mass spectrometry (GC-MS) measurements of the hydrocarbon species retained in SAPO-34-C after performing the MTH reaction revealed the 
a)

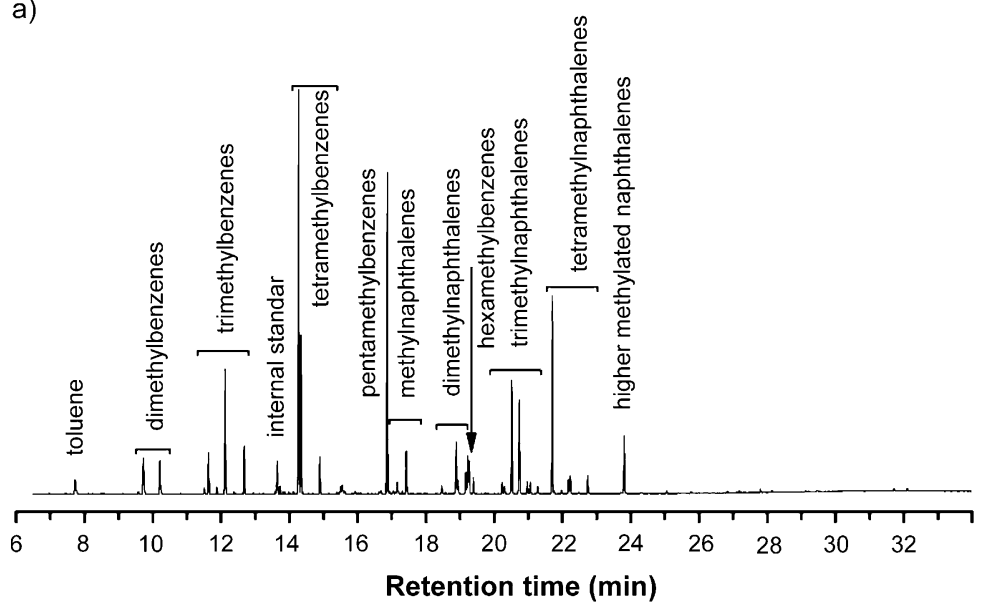

b)

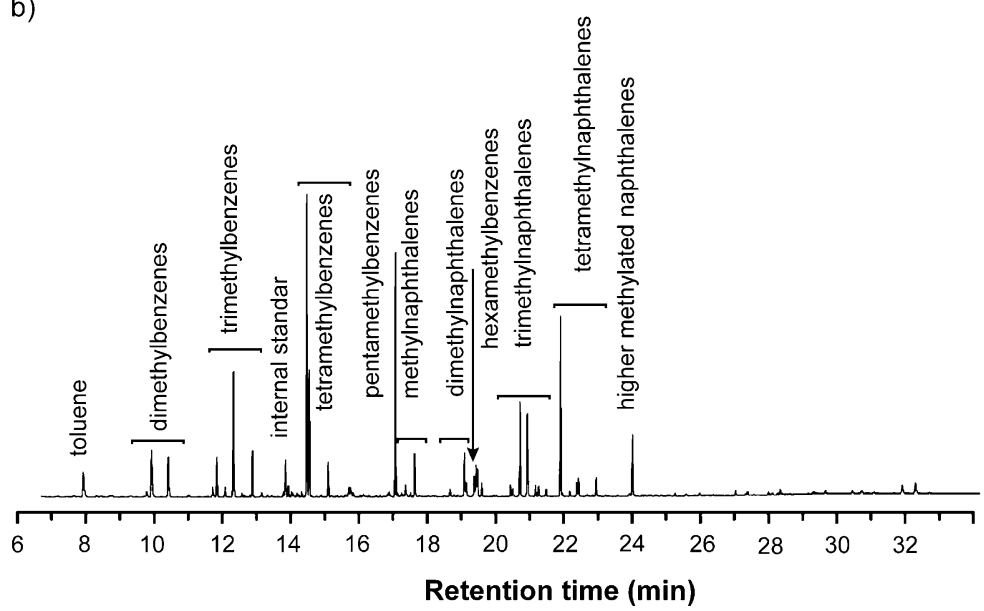

Figure 2. GC-MS analysis of the retained hydrocarbons in a) SAPO-34-C and b) SAPO-34$\mathrm{S}$ molecular sieves after the MTH reaction at $400^{\circ} \mathrm{C}$

presence of a mixture of methylbenzenes ( $M B$; i.e., tetraMB and pentaMB) and methylated naphthalenes, as illustrated in Figure $2 \mathrm{a}$, which is also characteristic for H-SAPO-34 molecular sieves.

To elucidate the effect of a severe hydrothermal treatment on the catalytic performance of H-SAPO-34 materials, SAPO-34$\mathrm{S}$ and SAPO-34-C were compared. The catalytic data for SAPO34-S are summarized in Figure $1 \mathrm{C}$, showing a shorter induction period and a $20-25 \%$ reduction in methanol conversion with respect to SAPO-34-C. The product selectivity, on the other hand, was similar for both H-SAPO-34 catalyst powders under investigation, presenting only a small increase in the production of aromatics within SAPO-34-S (Figure $1 \mathrm{~d}$ ). In line with the reaction selectivity, the retained hydrocarbon analysis performed after the MTH reaction on SAPO-34-S showed similar species to those present in the SAPO-34-C sample. The corresponding GC-MS data are given in Figure $2 \mathrm{~b}$. More specifically, SAPO-34-S contained a mixture of MBs (i.e., tetraMB and pentaMB) and methylated naphthalenes after reaction. In view of the results presented in Figure 1 and 2, it can be concluded that a hydrothermal treatment on H-SAPO-34 catalyst powders leads to a lower MTH activity and stability, without modifying the product selectivity.
Physicochemical changes by applying a severe hydrothermal treatment

To obtain detailed insight into the effect that a hydrothermal treatment has on the physicochemical properties of H-SAPO-34 materials nitrogen and carbon dioxide sorption, XRD, SEM, ammonia-TPD, and ${ }^{29} \mathrm{Si}$ and ${ }^{27} \mathrm{AI}$ MAS NMR measurements were performed on the SAPO-34-C and SAPO-34-S molecular sieves.

The nitrogen physisorption measurements indicated that the SAPO-34-C and SAPO-34-S molecular sieves are microporous materials with identical adsorption and desorption isotherms. In contrast, the carbon dioxide physisorption isotherms revealed a $23 \%$ reduction in the micropore volume of SAPO34-S. Both nitrogen and carbon dioxide sorption results are given in Table S1 and Figure S1 of the Supporting information. The XRD patterns of both samples under investigation revealed a loss of crystallinity as well as an increasing amount of amorphous material after steaming (Figure S2). The SEM microphotographs obtained before and after steaming showed an increased number of cracks for SAPO-34-S. These results, presented in Figure S3 of the Supporting information, suggest a partial destruction of the SAPO34 structure and a reduction in the effective diffusion path of reactants within the steamed catalyst powders.

Despite the fact that the structure of an acid site within H-SAPO-34 shares some similarities with that of $\mathrm{H}-\mathrm{ZSM}-5$, the acidity of microporous silicoaluminophosphates can differ considerably compared to that of microporous aluminosilicates. The acidity of SAPO34 molecular sieves arises if phosphorous atoms are replaced by silicon atoms, leading to a negatively charged framework that is balanced by protons attached to Si-O-Al bridges. ${ }^{[17-19]}$ Nonetheless, different types of acid sites can be present in SAPO-34 molecular sieves, as a result of the substitution of two neighboring phosphorous and aluminum atoms for two silicon atoms. This leads to the generation of silica patches in the SAPO structure, better known as silicon islands. ${ }^{[20,21]}$ Importantly, at high temperatures the H-SAPO framework can be (locally) separated into silicon domains and the $\mathrm{AlPO}_{4}$ phase. ${ }^{[20,22]}$ This transformation, which can take place during the oxidative treatments applied to regenerate the MTH catalysts, might induce significant changes in their physicochemical properties. More specifically, it has been reported that the formation of silicon islands leads to a reduction in the number of acid sites available for the MTH reaction and increases the acid strength of the Si-OH-Al species located at boundaries of the H-SAPO and the silicon island phases. ${ }^{[23-27]}$

To investigate the above-mentioned phenomena, TPD measurements with ammonia as a probe molecule were undertaken before and after applying a severe hydrothermal treatment. As shown in Figure $\mathrm{S} 4$ of the Supporting Information, both $\mathrm{H}$ SAPO-34 samples under study contained a combination of strong and weak acid sites, evidenced by the presence of two 
ammonia-TPD peaks occurring at low and high desorption temperatures. Nevertheless, as revealed by the reduction in the total area below the desorption curve of SAPO-34-S, a hydrothermal treatment leads to a decrease in the amount of acid sites. Interestingly, the decrease in peak intensity is more prominent at low desorption temperature for SAPO-34-S than at high desorption temperature, which suggests a selective reduction in the amount of weak acid sites during steaming.

To elucidate whether the differences observed in the TPD profiles of the SAPO-34-C and SAPO-34-S molecular sieves are related to redistribution of silicon atoms during steaming, both samples were studied with ${ }^{29} \mathrm{Si}$ MAS NMR. The results, given in Figure $3 \mathrm{a}$, show the presence of peaks at $\delta=-90$ and $-110 \mathrm{ppm}$ in the spectrum of SAPO-34-C. These peaks are at-

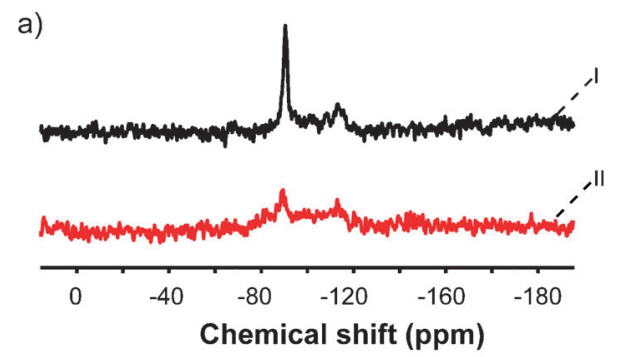

b)

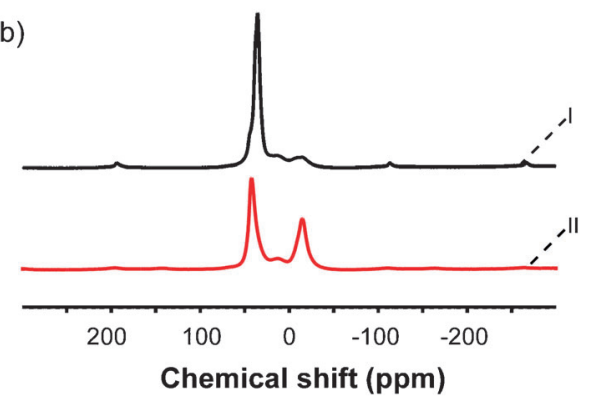

Figure 3. a) ${ }^{29} \mathrm{Si}$ and b) ${ }^{27} \mathrm{AI}$ MAS NMR spectra of I) SAPO-34-C and II) SAPO-34-S.

tributed to silicon atoms coordinated to four (Si(4AI)) or zero $(\mathrm{Si}(\mathrm{OAI}))$ aluminum atoms, respectively. ${ }^{[28]}$ Accordingly, the presence of the $\delta=-100 \mathrm{ppm}$ peak in the of SAPO-34-C reveals the existence of silicon islands in this sample. The spectrum of SAPO-34-S, on the other hand, discloses a significant reduction in the number of isolated silicon atoms as evidenced by the decrease in the intensity of the $\delta=-90 \mathrm{ppm}$ NMR peak. This observation is in line with previous studies performed on $\mathrm{H}$ SAPO-34 materials and indicates a redistribution of silicon atoms occurring at high steaming temperatures. ${ }^{[22,27]}$

Complementary to the ${ }^{29} \mathrm{Si}$ MAS NMR experiments, ${ }^{27} \mathrm{AI}$ MAS NMR measurements on the SAPO-34-C and SAPO-34-S molecular sieves were performed. As presented in Figure $3 \mathrm{~b}$, the spectrum of SAPO-34-C is characterized by peaks at around $\delta=60$ 50 and $0 \mathrm{ppm}$, indicative for the presence of a mixture of 4and 6-fold aluminum coordinated species, respectively. ${ }^{[29-31]}$ In the spectrum of SAPO-34-S, the variation of the above mentioned peaks is informative for a substantial increase in the amount of 6-fold aluminum species at the expense of 4-fold aluminum species. Furthermore, the spectrum of SAPO-34-S presents a resonance in the region of $\delta=30-35 \mathrm{ppm}$, attributed to 5 -fold aluminum. ${ }^{[32]}$ Consequently, the changes observed in the spectra of the SAPO-34-C and SAPO-34-S molecular sieves reveal an increased dislodgement of framework aluminum after a hydrothermal treatment.

\section{Nanoscale imaging of aluminum, silicon, and carbon deposits}

To investigate the differences in performance and physicochemical properties between SAPO-34-C and SAPO-34-S in more detail, STXM was used to generate chemical maps of silicon, aluminum, and carbon deposits, the latter in situ, making use of a specially designed nanoreactor.

Aluminum and silicon chemical maps were measured with STXM. The obtained contour maps, depicted in Figure 4, confirm the presence of silicon islands within the SAPO-34-C and

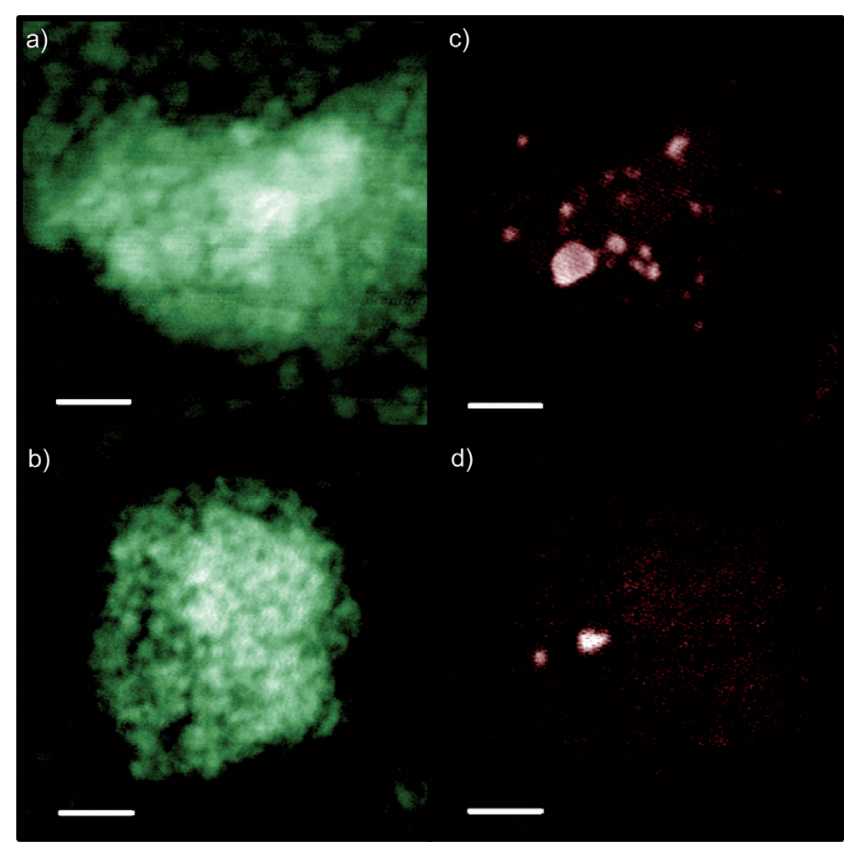

Figure 4. Aluminum 2-D STXM maps of a) SAPO-34-C and b) SAPO-34-S. Silicon 2-D STXM maps of c) SAPO-34-C and d) SAPO-34-S. The scale bar represents $1 \mu \mathrm{m}$ and the pixel size is $20 \mathrm{~nm}$.

SAPO-34-S molecular sieves. In both samples the silicon patches are heterogeneously distributed within the H-SAPO-34 matrix, with sizes extending up to a few hundred nanometers.

A series of stacks were obtained at the silicon K-edge to elucidate possible differences in the nature of the silicon species present in both samples under investigation. Interestingly, as depicted in Figure 5, the analysis of the silicon K-edge X-ray absorption (XA) spectra obtained from SAPO-34-C reveals more defined X-ray absorption near edge structure as compared to that obtained from SAPO-34-S molecular sieves. This 

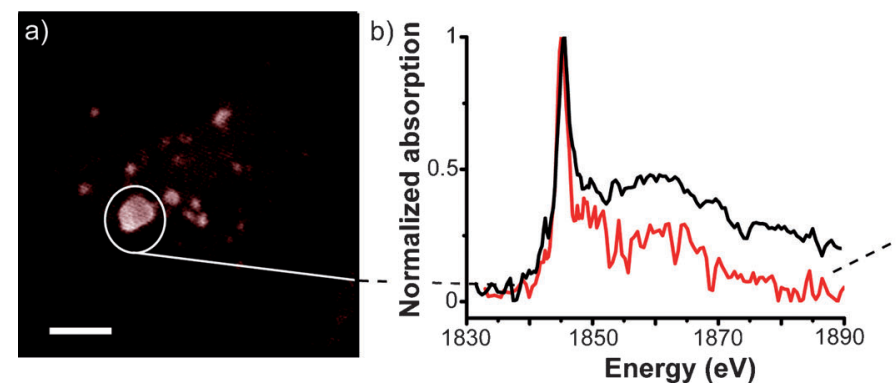

Figure 5. a) Silicon K-edge contour map of SAPO-34-C. b) Silicon K-edge X-ray absorption spectra of SAPO-34-C (black) and SAPO-34-S (red). c) Silicon K-edge contour map of SAPO-34-S. The scale bar represents $1 \mu \mathrm{m}$ and the pixel size is $20 \mathrm{~nm}$. The silicon X-ray absorption spectra were obtained collecting a series of images over small energy increments, subsequently combining these to form a spectral image sequence (stack) on the region of interest marked with white circles in (a) and (c).

observation suggests a partial amorphization of the framework after applying the hydrothermal treatment. ${ }^{[33]}$

STXM was applied in combination with an in situ micro-electro-mechanical system (MEMS) nanoreactor to gain insight into the nanoscopic phenomena, taking place at the level of a single catalyst particle during the MTH reaction. For this purpose, the absorption at the carbon K-edge was measured as a function of time on stream. The results for SAPO-34-C are shown in Figure 6. Among the features present in the carbon K-edge XA spectra, those appearing at 285, 287.6-288.2, 289.5, and $291-293.5 \mathrm{eV}$ correspond to transitions from the carbon $1 \mathrm{~s}$ to the unoccupied $\mathrm{C}=\mathrm{C} \pi^{*},{ }^{[34-38]} \mathrm{C}-\mathrm{H} \sigma^{*},{ }^{[37,39]} \mathrm{C}-\mathrm{OH} 3 \mathrm{p} / \sigma^{*[36]}$ and $\mathrm{C}-\mathrm{C} \sigma^{[40,41]}$ molecular orbitals, respectively. As shown in Figure $6 \mathrm{a}$, after $60 \mathrm{~min}$ of reaction the peaks arising as a result of $C=C \pi^{*}$ and $C-C \sigma$ bonds are not clearly defined in the carbon XA spectra of SAPO-34-C. Furthermore, STXM revealed local heterogeneities during the genesis of the species that constitute the catalytic scaffold in the hydrocarbon pool (HCP) mechanism. ${ }^{[42-44]}$ In particular, the spectrum arising from the outer regions of the SAPO-34-C aggregate exhibited more defined features than that of the inner aggregate regions. This points towards a faster formation of the carbonaceous species in the external regions of the H-SAPO-34 catalyst aggregate, being in agreement with studies performed on micron-sized H-SAPO-34 catalysts. ${ }^{[45,46]}$

For longer times on stream (i.e., $90 \mathrm{~min}$, Figure 6b), SAPO34-C displayed well-defined carbon K-edge XA spectra originating from the internal and external regions of the catalyst aggregate. The obtained carbon K-edge XA spectra, however, showed distinct spectral features as well as relative intensities. These differences can be attributed to the presence of discrete hydrocarbon phases heterogeneously distributed within the SAPO-34-C aggregates during MTH reaction. Most notably, the spectra originating from the inner regions of the SAPO-34-C aggregate showed a lower relative intensity of the $285 \mathrm{eV}$ peak with respect to the transitions located between 286 and $287 \mathrm{eV}$, which arise as a result of the presence of non-equivalent carbon atoms in a $\mathrm{sp}^{2}$ hybridization state. ${ }^{[4]}$ Importantly and as described in a previous publication, ${ }^{[12]}$ the latter transitions can be used as a fingerprint of coke precursor species in the carbon K-edge XA spectra since they originate from aro-

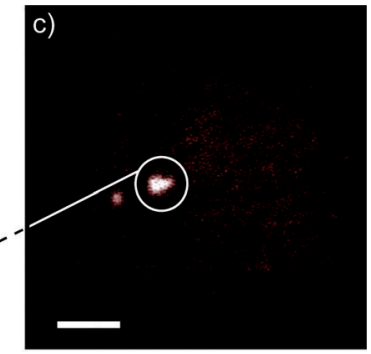

matic species with high symmetry (i.e., naphthalene and anthracene). To confirm this observation, the experimental carbon $X A$ spectrum obtained from the internal catalyst region has been compared in Figure S5 in the Supporting information with a series of reference compounds differing in their number of nonequivalent carbon atoms. This comparison shows that the modifications observed in the carbon K-edge XA spectra of SAPO-34-C are indicative for the existence of spatial heterogeneities in the distribution of coke precursor species within the calcined catalyst aggregates. More specifically, the coke precursor species are distributed in an egg-yolk fashion way within SAPO-34-C, being preferentially located in the inner regions of the aggregate.

To elucidate whether the spatiotemporal heterogeneities observed in the distribution of the generated hydrocarbon phases persist for longer times on stream, the same analysis was performed after $120 \mathrm{~min}$ of reaction. The results, summarized in Figure $6 c$, confirm the presence of an egg-yolk distribution of the hydrocarbon species. It is noted, however, that the spectral differences observed after $120 \mathrm{~min}$ of reaction decreased compared to a shorter time on stream. More specifically, the relative intensity ratio of the transitions located at $285 \mathrm{eV}$ with respect to those arising at $286.5 \mathrm{eV}$ increases in the internal regions of the catalyst aggregate from 1.3 to 1.6, being constant in the outer catalyst regions with a value of 2.1. In other words, this observation illustrates the dynamic character of the coke formation process over SAPO-34 catalysts during MTH reaction.

Previous studies performed on H-SAPO-34 materials have reported that the coke formation process does not end once the methanol flow has been stopped. ${ }^{[4]}$ To investigate these phenomena the absorption at the carbon K-edge was measured after the cooling period subsequent to reaction. As depicted in Figure $6 d$, a more homogeneous distribution of the hydrocarbon species was found throughout the catalyst aggregate after quenching the SAPO-34-C sample to room temperature. Accordingly, this result shows that certain catalyst regions are still active during the cooling period and highlights the importance of performing in-situ characterization studies to fully understand coke formation processes in molecular sieves at the nanometer scale.

In a similar manner to the analysis performed for the SAPO34-C molecular sieve, the reactivity of SAPO-34-S was characterized with the in situ STXM methodology. For comparison purposes, the STXM measurements were performed with the same settings as those used for SAPO-34-C. The results, presented in Figure 7, show a series of similar hydrocarbon spectra originating from different regions of the SAPO-34-S sample. Most notably, after $30 \mathrm{~min}$ of reaction SAPO-34-S showed the 

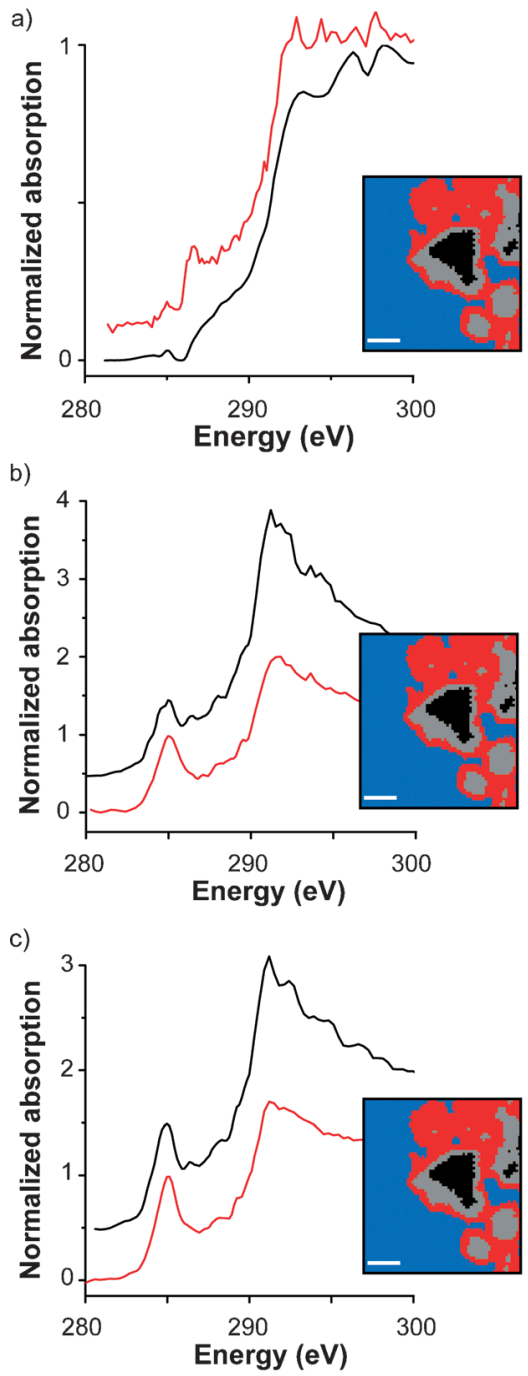

d)

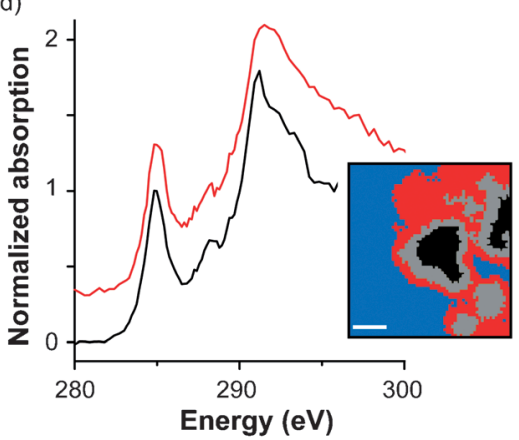

Figure 6. Carbon K-edge X-ray absorption spectra and cluster index obtained after a) 60 , b) 90 , and c) 120 min of reaction for SAPO-34-C. d) Carbon K-edge X-ray absorption spectra and cluster index obtained after the cooling period subsequent to reaction for SAPO-34-C. The colored regions in the cluster index correspond to the aggregate regions from which the spectra with the same color coding were obtained. The scale bar represents $500 \mathrm{~nm}$.

presence of well-defined carbon K-edge XA spectra originating from both the outer and inner catalyst regions. This is in contrast with the situation described for SAPO-34-C and can be reasonably attributed to a shorter $\mathrm{MTH}$ induction period after performing a hydrothermal treatment.
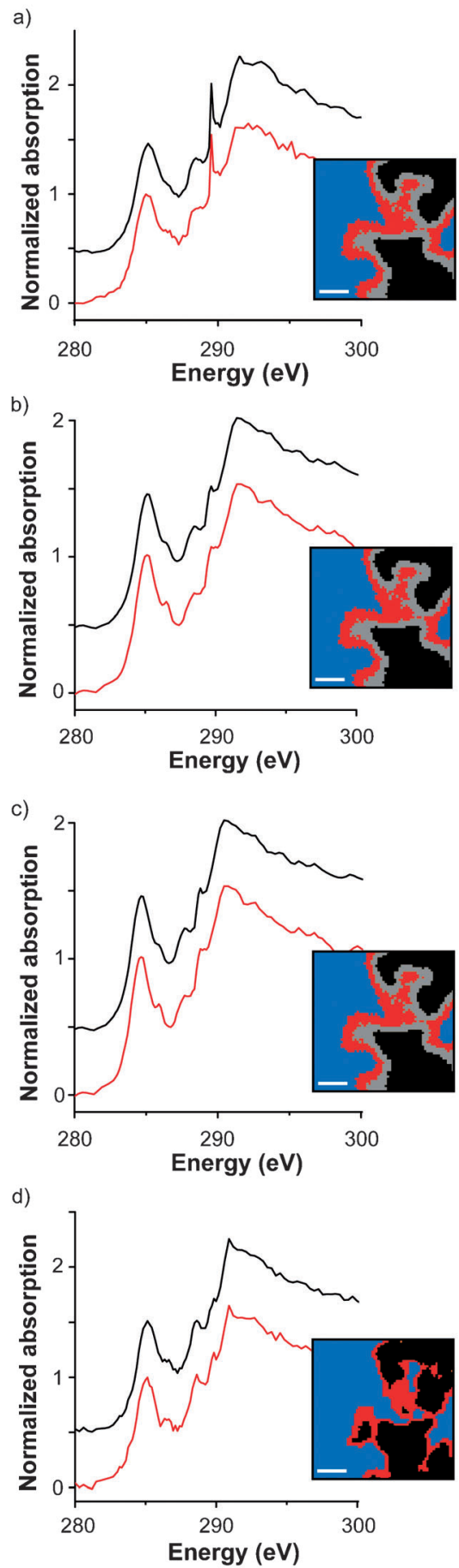

Figure 7. Carbon K-edge X-ray absorption spectra and cluster index obtained after a) 30, b) 90 , and c) 120 min of reaction for SAPO-34-S. d) Carbon K-edge X-ray absorption spectra and cluster index obtained after the cooling period subsequent to reaction for SAPO-34-S. The colored regions in the cluster index correspond to the aggregate regions from which the spectra with the same color coding were obtained. The scale bar represents $500 \mathrm{~nm}$.

For longer reaction times, namely 90 and $120 \mathrm{~min}$, the carbon K-edge XA spectra obtained from the inner and outer regions of the SAPO-34-S aggregates displayed the same features with similar intensity ratios. This observation is in contrast with the results obtained from SAPO-34-C and reveals the 
presence of similar hydrocarbon species throughout the SAPO34-S catalyst aggregate at different times on stream. This is depicted in Figure $7 \mathrm{~b}-\mathrm{c}$.

As shown in Figure $7 d$, after the cooling period subsequent to reaction a similar increase in the peak appearing between 287.6 and $288.2 \mathrm{eV}$ was observed in the carbon K-edge XA spectra arising from the inner and outer regions of the SAPO34-S aggregate. This observation indicates that all regions within SAPO-34-S catalyst powders display a similar activity during the cooling period subsequent to reaction.

Interestingly, it should be noted that the above described egg-yolk distribution of coke precursor species found within SAPO-34-C presents important differences with the core-shell distribution observed for calcined H-ZSM-5 zeolite powders. ${ }^{[11]}$ More specifically, the preferential distribution of coke precursor species in the outer regions of the H-ZSM- 5 catalyst particles, as shown in Figures $8 \mathrm{a}$ and $8 \mathrm{~b}$, induces severe diffusion limitations for longer reaction times. In contrast to calcined H-ZSM5 , the deactivation of the SAPO-34-C sample during MTH is not

ces between both archetype MTH catalyst materials. In particular, in the case of H-ZSM-5 zeolite powders steaming has a negative influence on the MTH activity, but a positive effect on the MTH stability. This modification finds its origin in the limited production of coke precursor species, as a result of a decrease in the number and strength of the acid sites in combination with the introduction of mesoporosity after steaming, as shown in Figures $8 \mathrm{c} 8 \mathrm{~d}$. In the case of H-SAPO-34, however, steaming negatively impacts the MTH activity and stability, causing a rapid and prominent formation of coke precursor species within SAPO-34-S. The main differences during the hydrothermal treatment of both catalysts arise from the relatively well-preserved strong Brønsted acidity and the lack of mesoporosity in H-SAPO-34 catalyst powders.

\section{Conclusions}

The reactivity of a H-SAPO-34 molecular sieve has been investigated during the MTH reaction at $400^{\circ} \mathrm{C}$ with in situ STXM showing important differences with the other archetype MTH catalyst material, zeolite ZSM-5. Catalytic testing reveals a high selectivity towards light olefins, a rapid loss of activity, and a prominent formation of highly substituted methylbenzenes and poly-aromatic species during MTH. Interestingly, in situ STXM shows a heterogeneous and dynamic formation of coke precursor species within the calcined H-SAPO-34 material. Most notably, in the beginning of the reaction coke precursor species formation is preferentially favored in the core of the catalyst aggregate. With further methanol addition coke precursor species formation becomes more important in the external regions of the catalyst aggregate, progressively filling the entire SAPO-34 catalyst particle.

Comparison of calcined and

determined by the preferential formation of coke precursor species at the outer rim of the catalyst particle. In this case, the coke precursor species are initially formed in the inner regions of the catalyst particle, progressively filling the whole particle with increasing reaction times. Accordingly, the deactivation of calcined H-SAPO-34 is most probably determined by the progressive deposition of carbonaceous species on the acid sites rather than by the strong diffusion limitations at the external regions of the catalyst particle. This is schematically illustrated in Figure 8.

Additionally, it has been observed that the performance of a severe hydrothermal treatment leads to important differen- a severely steamed H-SAPO-34 discloses important changes in both their physicochemical properties and reactivity during MTH. More specifically, of a severe hydrothermal treatment partially destroys the SAPO-34 framework and increases the amount of cracks present within the catalyst samples. Furthermore, a redistribution of the silicon species contained in the $\mathrm{H}$ SAPO-34 matrix has been found after steaming, which decreases the degree of crystallinity of the catalyst material as well as its number of acid sites. Importantly, the physicochemical changes taking place during a hydrothermal treatment result in a decrease in both MTH activity and stability, without modifying the product selectivity. In situ STXM at the carbon K-edge 
during MTH has revealed a relation between the lower MTH stability of steamed H-SAPO-34 and the rapid and more prominent generation of coke precursor species as compared to calcined H-SAPO-34.

\section{Experimental Section}

Two sets of H-SAPO-34 catalyst powders, namely a calcined (sample name: SAPO-34-C) and a hydrothermally treated sample (sample name: SAPO-34-S), have been investigated. The starting material, with dimensions of approximately $200-800 \mathrm{~nm}$, is a sample with a $\mathrm{Si} /(\mathrm{Si}+\mathrm{Al}+\mathrm{P})$ ratio of 0.037 . To obtain the SAPO34-P sample the template of the as-prepared H-SAPO-34 material was removed by calcination at $650^{\circ} \mathrm{C}\left(5^{\circ} \mathrm{Cmin}^{-1}, 360 \mathrm{~min}\right)$ in a quartz tubular oven (Thermoline 79300). Subsequently, SAPO-34$P$ was ion exchanged with a $10 \mathrm{wt} . \%$ ammonium nitrate solution (Acros Organic, $99+\%$ ) at $70^{\circ} \mathrm{C}$. After a waiting time of 30 days, SAPO-34-C was obtained by calcination at $650^{\circ} \mathrm{C}\left(5^{\circ} \mathrm{Cmin}^{-1}\right.$, $360 \mathrm{~min}$ ) in a static oven (N100 Nabertherm). SAPO-34-S was obtained performing a hydrothermal treatment on SAPO-34-C in a quartz tubular oven (Thermoline 79300). In the steaming treatment the sample was first preheated at $120^{\circ} \mathrm{C}\left(30 \mathrm{~min}, 2^{\circ} \mathrm{Cmin}^{-1}\right)$ subsequently increasing the temperature to $700^{\circ} \mathrm{C}\left(5^{\circ} \mathrm{Cmin}^{-1}\right.$, $180 \mathrm{~min})$ under a nitrogen flow $\left(180 \mathrm{~mL} \mathrm{~min}^{-1}\right)$ saturated with water at $100^{\circ} \mathrm{C}$. After the hydrothermal treatment, SAPO-34-S was calcined at $650^{\circ} \mathrm{C}\left(5^{\circ} \mathrm{Cmin}^{-1}, 360 \mathrm{~min}\right)$ in a static oven (N100 Nabertherm).

Magic angle spinning (MAS) NMR experiments were performed at 11.7 T on a Bruker Avance III spectrometer. The ${ }^{27} \mathrm{AI}$ MAS NMR experiments used a $3.2 \mathrm{~mm}$ triple resonance MAS probe, whereas the ${ }^{29} \mathrm{Si}$ MAS NMR experiments were performed using a $4 \mathrm{~mm}$ double resonance MAS probe. The ${ }^{27} \mathrm{AI}$ MAS NMR spectra were obtained using $\pi / 12$ pulses at a rf-field of $94 \mathrm{kHz}, 10000$ scans and with a recycle delay of $0.5 \mathrm{~s}$. The MAS rate was $20 \mathrm{kHz}$ for the ${ }^{27} \mathrm{Al}$ MAS NMR. The ${ }^{29} \mathrm{Si}$ MAS NMR spectra were obtained using $\pi / 2$ pulses at a rf-field of $38.4 \mathrm{kHz}, 6000$ scans and with a recycle delay of $40 \mathrm{~s}$ at a MAS rate of $10 \mathrm{kHz}$. The chemical shifts of ${ }^{27} \mathrm{Al}$ and ${ }^{29} \mathrm{Si}$ were externally referenced to $1 \mathrm{M}$ aluminum nitrate $\left(\mathrm{Al}\left(\mathrm{NO}_{3}\right)_{3}(\mathrm{aq})\right)$ and the sodium salt of 4,4-dimethyl-4-silapentane-1-sulfonic acid (DSS sodium salt), respectively.

Catalyst testing was performed without pressing and sieving the catalyst. In each case $30 \mathrm{mg}$ of catalyst material were used and the reaction temperature was set at $400^{\circ} \mathrm{C}$. The $\mathrm{MTH}$ reaction products were analyzed with an online gas chromatography (GC) connected to the outlet of a fixed bed reactor (i.d., $10 \mathrm{~mm}$ ) using a heated transfer line. The inlet of the reactor was connected to helium, which was bubbled through methanol (Antonides-Interchema, $99 \%)$ kept at $20^{\circ} \mathrm{C}\left(P_{\mathrm{MeOH}}=130 \mathrm{mbar}\right)$ in a saturation evaporator (weight hourly space velocity $=5.56 \mathrm{gg}^{-1} \mathrm{~h}^{-1}$ ). The first GC analysis of the effluent product was performed after $5 \mathrm{~min}$ on stream. Subsequent to reaction, $15 \mathrm{mg}$ of the deactivated catalyst sample were transferred to a Teflon tube into which $1 \mathrm{~mL}$ of $15 \%$ hydrofluoric acid was added. After a waiting time of $30 \mathrm{~min}, 1 \mathrm{~mL}$ of dichloromethane, containing hexachloroethane as internal standard was added to the Teflon tube. Then, $1 \mu \mathrm{L}$ of the resulting organic phase was analyzed in an Agilent $6890 \mathrm{~N} \mathrm{GC}$ equipped with an Agilent 5793 mass selective (MS) detector. An HP-5 MS column $(60 \mathrm{~m}, 0.25 \mathrm{~mm}$ i.d., stationary phase thickness $0.25 \mu \mathrm{m})$ and an inlet split of 1:5 were used for this purpose.

In situ scanning transmission X-ray microscopy (STXM) experiments were performed on the interferometrically controlled STXM micro- scope at beamline 11.0.2 of the advanced light source (ALS) of the Lawrence Berkeley National Laboratory (LBNL, Berkeley, USA) ${ }^{[48]}$ To obtain information under realistic working conditions a micro-electro-mechanical system (MEMS) nanoreactor ${ }^{[49]}$ was used in combination with a $40 \mathrm{~nm}$ zone plate. Prior to MTH, SAPO-34-C and SAPO-34-S were activated at $450^{\circ} \mathrm{C}$ flowing helium $\left(2 \mathrm{~mL} \mathrm{~min}^{-1}\right)$ during $30 \mathrm{~min}$. Afterwards, the temperature was decreased to $400^{\circ} \mathrm{C}$ and methanol (Antonides-Interchema, 99\%) was introduced by means of saturation of the helium flow $\left(2 \mathrm{~mL} \mathrm{~min}^{-1}\right)$ at $0{ }^{\circ} \mathrm{C}$ during $180 \mathrm{~min}$. Aluminum and silicon chemical contour maps were obtained using the pre-edge and edge images, after being aligned and converted to optical density with the aXis2000 software package (http://unicorn.mcmaster.ca/aXis2000.html). The preedge image ( $1560 \mathrm{eV}$ for aluminum and $1835 \mathrm{eV}$ for silicon) was subtracted from the edge image $(1565.5 \mathrm{eV}$ for aluminum and $1845 \mathrm{eV}$ for silicon) resulting in the contour map. The absorption at the carbon K-edge was characterized collecting a series of images over small energy increments, combining these to form a spectral image sequence (stack). More specifically, the stacks were obtained in the range of $280-320 \mathrm{eV}$ using an energy resolution of $0.15 \mathrm{eV}$. After aligning the image sequence, a principal component analysis (PCA) was used to obtain the primary components in the data set. ${ }^{[50]}$ Subsequently, a cluster analysis was performed to classify pixels according to similarities in their spectra. ${ }^{[51]}$ For comparison purposes all the carbon K-edge $\mathrm{X}$-ray absorption spectra obtained from the cluster analysis have been normalized to the peak located at $285 \mathrm{eV}$. The pixel size used in the image sets was $40 \mathrm{~nm}$. The absorption at the silicon K-edge was characterized collecting a series of stacks in the range of $1830-1890 \mathrm{eV}$ using an energy resolution of $0.2 \mathrm{eV}$. Afterwards, a PCA and a cluster analysis were performed to classify pixels according to similarities in their spectra. The STXM data was analyzed using aXis2000 software.

\section{Acknowledgements}

Dr. M. Mertens and Dr. E. de Smit (both from ExxonMobil, Machelen, Belgium), H. van der Bij and U. Deka (both from Utrecht University, The Netherlands), Dr. S. Svelle (Oslo University, Norway), as well as Dr. T. Tyliszczak and Dr. A.L.D. Kilcoyne (both from Lawrence Berkeley National Laboratory, USA) are kindly thanked for their contributions.

Keywords: carbon - hydrocarbons $\cdot$ hydrothermal treatment molecular sieves $\cdot$ X-ray absorption

[1] J. F. Haw, W. G. Song, D. M. Marcus, J. B. Nicholas, Acc. Chem. Res. 2003 36, 317.

[2] M. Stöcker, Microporous Mesoporous Mater. 1999, $29,3$.

[3] H. Schulz, Catal. Today 2010, 154, 183.

[4] F. J. Keil, Microporous Mesoporous Mater. 1999, 29, 49.

[5] Z. Liu, J. Liang, Solid State Mater. Sci. 1999, 4, 80.

[6] C. D. Chang, A. J. Silvestri, J. Catal. 1977, 47, 249.

[7] C. D. Chang, Catal. Rev. Sci. Eng. 1983, 25, 1.

[8] U. Olsbye, S. Svelle, M. Bjørgen, P. Beato, T. V. W. Janssens, F. Joensen, S. Bordiga, K. P. Lillerud, Angew. Chem. 2012, 124, 5910; Angew. Chem. Int. Ed. 2012, 51, 5810.

[9] B. Arstad, S. Kolboe, Catal. Lett. 2001, 71, 209.

[10] Introduction to Zeolite Science and Practice (Eds.: H. van Bekkum, E. M. Flanigen, P. A. Jacobs, J. C. Jansen), Elsevier, Amsterdam, 2001.

[11] Structure-Activity and Selectivity Relationships in Heterogeneous Catalysis (Eds.: R. K. Graselli, A. W. Sleight), Elsevier, Amsterdam, 1990. 
[12] L. R. Aramburo, E. de Smit, B. Arstad, M. M. van Schooneveld, L. Sommer, A. Juhin, T. Yokosawa, H. W. Zandbergen, U. Olsbye, F. M. F. de Groot, B. M. Weckhuysen, Angew. Chem. 2012, 124, 3676; Angew. Chem. Int. Ed. 2012, 51, 3616.

[13] J. F. Haw, D. M. Marcus, Top. Catal. 2005, 34, 41.

[14] M. Briend, R. Vomscheid, M. J. Peltre, P. P. Man, D. Barthomeuf, J. Phys. Chem. 1995, 99, 8270.

[15] R. Vomscheid, M. Briend, M. J. Peltre, P. Massiani, P. P. Man, D. Barthomeuf, J. Chem. Soc., Chem. Commun. 1993, 554.

[16] M. J. G. Janssen, W. M. van Oorschot, K. R. Clem, US Patent 6,825,391 B2, 2004

[17] G. Müller, J. Bodis, G. EderMirth, J. Kornatowski, J. A. Lercher, J. Mol. Struct. 1997, 410, 173.

[18] G. Müller, E. Bodis, J. Kornatowski, J. A. Lercher, Phys. Chem. Chem. Phys. 1999, 1, 571.

[19] R. Raja, J. M. Thomas, M. Greenhill-Hooper, V. Doukova, Chem. Commun. 2007, 1924

[20] A. Buchholz, W. Wang, M. Xu, A. Arnold, M. Hunger, Microporous Mesoporous Mater. 2002, 56, 267.

[21] G. Sastre, D. W. Lewis, C. R. A. Catlow, J. Mol. Catal. A Chem. 1997, 119, 349.

[22] M. Derewinski, M. J. Peltre, M. Briend, D. Barthomeuf, P. P. Man, J. Chem Soc. Faraday Trans. 1993, 89, 1823.

[23] D. Barthomeuf, Zeolites 1994, 14, 394.

[24] J. A. Martens, P. J. Grobet, P. A. Jacobs, J. Catal. 1990, 126, 299.

[25] B. L. Su, A. Lamy, S. Dzwigaj, M. Briend, D. Barthomeuf, Appl. Catal. A 1991, 75, 311

[26] B. L. Su, D. Barthomeuf, J. Catal. 1993, 139, 81.

[27] M. J. Peltre, P. P. Man, M. Briend, M. Derewinski, D. Barthomeuf, Catal. Lett. 1992, 16, 123.

[28] G. A. V. Martins, G. Berlier, S. Coluccia, H. O. Pastore, G. B. Superti, G. Gatti, L. Marchese, J. Phys. Chem. C 2007, 111, 330.

[29] S. M. Campbell, D. M. Bibby, J. M. Coddington, R. F. Howe, R. H. Meinhold, J. Catal. 1996, 161, 338.

[30] S. M. Cabral de Menezes, Y. L. Lam, K. Damodaran, M. Pruski, Microporous Mesoporous Mater. 2006, 95, 286.

[31] R. Jelinek, B. F. Chmelka, Y. Wu, P. J. Grandinetti, A. Pines, P. J. Barrie, J. Klinowski, J. Am. Chem. Soc. 1991, 113, 4097.

[32] J. Chen, T. Chen, N. Guan, J. Wang, Catal. Today 2004, 93, 627.
[33] X-ray Absorption: Principles, Applications, Techniques of EXAFS, SEXAFS, and XANES (Eds.: D. C. Koningsberger, R. Prins), Wiley, New York, 1988.

[34] S. Bernard, O. Beyssac, K. Benzerara, N. Findling, G. Tzvetkov, G. E. Brown, Carbon 2010, 48, 2506.

[35] E. Najafi, J. A. Wang, A. P. Hitchcock, J. W. Guan, S. Denommee, B. Simard, J. Am. Chem. Soc. 2010, 132, 9020.

[36] H. A. Katzman, P. M. Adams, T. D. Le, C. S. Hemminger, Carbon 1994, 32, 379.

[37] P. R. Haberstroh, J. A. Brandes, Y. Gelinas, A. F. Dickens, S. Wirick, G. Cody, Geochim. Cosmochim. Acta 2006, 70, 1483.

[38] Y. Zubavichus, A. Shaporenko, V. Korolkov, M. Grunze, M. Zharnikov, J. Phys. Chem. B 2008, 112, 13711.

[39] D. Solomon, J. Lehmann, J. Kinyangi, B. Liang, K. Heymann, L. Dathe, K. Hanley, S. Wirick, C. Jacobsen, Soil Sci. Soc. Am. J. 2009, 73, 1817.

[40] A. P. Hitchcock, D. C. Newbury, I. Ishii, J. Stöhr, J. A. Horsley, R. D. Redwing, A. L. Johnson, F. Sette, J. Chem. Phys. 1986, 85, 4849.

[41] A. P. Hitchcock, I. Ishii, J. Electron Spectrosc. Relat. Phenom. 1987, 42, 11.

[42] I. M. Dahl, S. Kolboe, Catal. Lett. 1993, 20, 329.

[43] I. M. Dahl, S. Kolboe, J. Catal. 1994, 149, 458.

[44] I. M. Dahl, S. Kolboe, J. Catal. 1996, 161, 304.

[45] B. P. C. Hereijgers, F. Bleken, M. H. Nilsen, S. Svelle, K. P. Lillerud, M. Bjørgen, B. M. Weckhuysen, U. Olsbye, J. Catal. 2009, 264, 77

[46] D. Mores, E. Stavitski, M. H. F. Kox, J. Kornatowski, U. Olsbye, B. M. Weck huysen, Chem. Eur. J. 2008, 14, 11320.

[47] M. L. Gordon, D. Tulumello, G. Cooper, A. P. Hitchcock, P. Glatzel, O. C. Mullins, S. P. Cramer, U. Bergmann, J. Phys. Chem. A 2003, 107, 8512

[48] A. L. D. Kilcoyne, T. Tyliszczak, W. F. Steele, S. Fakra, P. Hitchcock, K Franck, E. Anderson, B. Harteneck, E. G. Rightor, G. E. Mitchell, A. P. Hitchcock, L. Yang, T. Warwick, H. Ade, J. Synchrotron Radiat. 2003, 10, 125.

[49] J. F. Creemer, S. Helveg, G. H. Hoveling, S. Ullmann, A. M. Molenbroek, P. M. Sarro, H. W. Zandbergen, Ultramicroscopy 2008, 108, 993.

[50] Q. Wang, J. C. Hanson, A. I. Frenkel, J. Chem. Phys. 2008, 129, 234502.

[51] M. Lerotic, C. Jacobsen, T. Schafer, S. Vogt, Ultramicroscopy 2004, 100, 35

Received: September 21, 2012

Published online on March 7, 2013 